\title{
Erratum to: Comparative Analysis of Antigen-Targeting Sequences Used in DNA Vaccines
}

\author{
Joana A. Carvalho - Adriano R. Azzoni • \\ Duarte M. F. Prazeres • Gabriel A. Monteiro
}

Published online: 29 August 2010

(C) Springer Science+Business Media, LLC 2010

\section{Erratum to: Mol Biotechnol \\ DOI 10.1007/s12033-009-9229-x}

The LAMP sequence shown in Table 1 in the original publication is not correct. The sequence cloned into
pISGlamp, pe1aISGlamp, pTSAlamp and pe1aTSAlamp constructs is: L I P I A V G G A L A G L V L I V L I A Y L I G R K R S H A G Y Q T I. The updated table should appear as follows.

Table 1 Features of ten plasmids encoding either $I S G$ or $n T S A$ genes located upstream of the reporter gene GFP

\begin{tabular}{llclc}
\hline Plasmid & Targeting sequence & Cloned sequence & Expected outcome \\
\hline pISGlamp & Lysosomal-associated & $5^{\prime}$ ISG GFP L I P I A V G G A L A G L V L I V L I A Y L I & Lysosomes and late \\
& membrane protein (lamp) & G R K R S H A G Y Q T I 3' & endosomes \\
pe1aISGlamp & Adenovirus E1A ER (e1a) & $5^{\prime}$ MRYMILGLLALAAVCSA ISG GFP L I P I A V G G A L A & Lysosomes and late \\
& + lamp & G L V L I V L I A Y L I G R K R S H A G Y Q T I 3' & endosomes \\
pTSAlamp & Lysosomal-associated & $5^{\prime}$ TSA GFP L I P I A V G G A L A G L V L I V L I A Y L I & Lysosomes and late \\
& membrane protein (lamp) & G R K R S H A G Y Q T I 3 & endosomes \\
pe1aTSAlamp & adenovirus E1A ER (e1a) & $5^{\prime}$ MRYMILGLLALAAVCSA TSA GFP L I P I A V G G A L A & Lysosomes and late \\
& + lamp & G L V L I V L I A Y L I G R K R S H A G Y Q T I 3' & endosomes \\
\hline
\end{tabular}

The online version of the original article can be found under doi:10.1007/s12033-009-9229-x.

J. A. Carvalho - A. R. Azzoni - D. M. F. Prazeres .

G. A. Monteiro ( $\square)$

IBB-Institute for Biotechnology and Bioengineering,

Centre for Biological and Chemical Engineering, Instituto

Superior Técnico, Av. Rovisco Pais. Torre Sul,

1049-001 Lisbon, Portugal

e-mail: gabmonteiro@ist.utl.pt 